Original Research Paper

\title{
Penggunaan Sistem Persekitaran Pembelajaran Maya Frog di Sekolah-Sekolah Malaysia: Pengalaman dan Prospek Masa Depan
}

\author{
Mohd Faiz Mohd Baharan' ${ }^{1}$, Noraizan Mohsin ${ }^{1}$, Mohd Nor Mamat ${ }^{1}$, Zawawi Temyati ${ }^{1}$ \\ ${ }^{1}$ Akademi Pengajian Islam Kontemporari, UiTM Shah Alam. Selangor, Malaysia.
}

Article History
Received:
29.07.2019
Revised:
01.09 .2019
Accepted:
05.10 .2019
*Corresponding Author:
Mohd Faiz Mohd Baharan
Email:
fazries@yahoo.com.my

Article History

Received:

Revised:

\section{Accepted:}

*Corresponding Author: Email:

fazries@yahoo.com.my
Abstrak: Penggunaan sistem Virtual Learning Environment Frog (VLE Frog) merupakan satu sistem pembelajaran maya yang giat digunakan di hampir 100.000 buah sekolah di seluruh negara. Sistem ini merupakan satu platform pembelajaran maya yang boleh diguna pakai oleh semua murid, guru dan warga sekolah pada bila-bila masa dan di mana sahaja untuk mengakses laman pendidikan. Namun, penggunaannya masih berada di tahap yang kurang memberangsangkan dan tidak di ambil berat oleh guru di sekolah. Justeru kajian ini dijalankan bagi mengenal pasti fungsi dan peranan sistem VLE Frog di sekolah. Kajian ini merupakan kajian gabungan kuantitatif dan kualitatif dengan melibatkan 367 orang sebagai sampel kajian. Kajian perpustakaan, instrumen soal selidik dan pemerhatian telah dijalankan bagi mendapatkan data kajian ini. Hasil dapatan kajian ini diharap dapat menjadi salah satu daripada kayu ukur terhadap kesediaan guru sekolah rendah dalam menggunakan teknologi dalam pendidikan khususnya melalui sistem VLE Frog.

Kata Kunci: VLE Frog, Sekolah Rendah, Guru.

Use of Frog Virtual Learning Environment System in Malaysian Schools: Future Experiences and Prospects

Abstract: The use of the Virtual Learning Environment Frog (VLE Frog) system is a powerful virtual learning system used in nearly 100,000 schools across the country. The system is a virtual learning platform that can be used by all students, teachers and schoolmates anytime and anywhere to access educational sites. However, its use is still at a disadvantage and has not been taken seriously by teachers in schools. Therefore, this study was conducted to identify the function and role of the VLE Frog system in schools. This study was a quantitative and qualitative study involving 367 people as a sample. Library surveys, questionnaires and observations were conducted to obtain data from this study. The findings of this study are expected to be one of the benchmarks for primary school teachers' readiness to use technology in education especially through the VLE Frog system.

Keywords: VLE Frog, Primary School, Teacher. 


\section{Pendahuluan}

Sistem Virtual Learning Environment Frog atau VLE Frog telah diperkenalkan oleh Kementerian Pendidikan Malaysia (KPM) sebagai antara salah satu bahan bantu mengajar yang interaktif dan sangat sesuai digunakan dalam sistem pendidikan di Malaysia. Aplikasi VLE Frog merupakan sistem pembelajaran di sekolah yang berasaskan web yang menyamai dengan suasana pembelajaran sebenar di dalam bilik darjah. Konsep pembelajaran ini adalah integrasi antara konsep pembelajaran konvensional dengan konsep pembelajaran maya. Aplikasi ini telah diistilahkan sebagai intranet iaitu pembelajaran bilik darjah secara online dan ruang sosial untuk sekolah berhubung hanya di dalam satu bumbung [1]. Pelaksanaan aplikasi VLE Frog sebagai aplikasi pengurusan pembelajaran secara maya adalah usaha kementerian untuk merevolusikan proses pengajaran dan pembelajaran di sekolahsekolah di Malaysia bersesuaian dengan suasana pendidikan abad ke-21.

Menurut Mohamed Amin Embi [2], guru abad ke-21 seharusnya mempunyai empat ciri utama iaitu mampu memberi kesedaran kepada pelajar dan pembelajaran abad ke-21, mampu mentransformasikan pengajaran bagi mempersiagakan pelajar untuk masa yang akan datang, mampu mengabadkan kurikulum agar relevan dengan pendidikan abad ke-21 dan pengajaran guru ke arah budaya pengajaran hijau, digital dan global.

Kajian UNESCO pada tahun 2012 mendapati penggunaan teknologi maklumat tidak berganjak daripada sekadar penggunaan aplikasi pemprosesan perkataan sebagai alat pengajaran [3]. Laporan Ketua Audit Negara [4] pula melaporkan kos yang dibelanjakan tidak berbaloi dengan impak (ROI) terhadap pelajar di sekolah. Hal ini dibuktikan lagi dengan penggunaan aplikasi VLE Frog pada 10 000 buah sekolah di Malaysia, hanya lima peratus sahaja yang memanfaatkan dan menggunakan aplikasi VLE Frog yang disediakan secara percuma bagi menjalankan pengajaran dan pembelajaran secara maya [4]. Berdasarkan keperluan memperkasakan bidang pendidikan terutamanya meningkatkan kualiti guru dalam PPPM 2013-2025, penyelidik berpendapat perlunya kajian tentang penggunaan sistem VLE Frog dalam kalangan guru di sekolah dengan tujuan mencari penyelesaian masalah dan menambah baik penggunaan sistem VLE Frog.

\section{Penyataan Masalah}

Merujuk kepada laporan yang dikeluarkan oleh Ketua Audit Negara Siri 3 Tahun 2013 menyatakan bahawa penggunaan VLE Frog pada golongan sasaran iaitu golongan murid, golongan guru dan golongan ibu bapa mendapati kadar penggunaan adalah rendah. Hal menunjukkan tahap penggunaan adalah pada nilai 0.01 peratus hingga 4.69 peratus sahaja. Hal ini turut disokong dengan kajian yang dijalankan oleh Nor Azlah \& Fariza [5] mendapati jumlah penggunaan bulan November 2012 hingga bulan Februari 2013 dalam kalangan guru adalah sangat sedikit dan lemah. Rentetan itu, pada awal bulan Januari 2015 pihak KPM telah mengeluarkan satu surat siaran Bil. 1/2015 untuk memastikan penggunaan VLE Frog di sekolah dijalankan secara optimum [6].

\section{Objektif Kajian}

Kajian ini dijalankan bagi mencapai objektif khusus yang berikut iaitu;

1. Mengenal pasti fungsi dan peranan sistem VLE Frog pada peringkat sekolah rendah di Malaysia,

2. Mengenal pasti faktor yang mendorong keberkesanan penggunaan VLE Frog di peringkat sekolah rendah di Malaysia,

3. Mencadangkan penyelesaian terhadap masalah yang dihadapi bagi penggunaan VLE Frog di peringkat sekolah rendah di Malaysia.

\section{Tinjauan Literatur}

Sistem ini merupakan satu Projek Perkhidmatan 1Bestarinet (1Bestarinet) yang dilaksanakan dengan kerjasama YTL Communication Sdn. Bhd bagi menggantikan dan menambah baik sistem rangkaian ICT di sekolah-sekolah yang telah tamat kontraknya pada 31 Disember 2010 (Kementerian Pendidikan Malaysia, 2010). Projek ini telah memperlihatkan hampir 10,000 buah sekolah di serata Malaysia dilengkapkan dengan akses internet berkelajuan tinggi dan platform pembelajaran maya melalui pengaplikasian jaringan internet berkelajuan tinggi dan dapat mengakses kepada penyelesaian pendidikan bersepadu bertaraf dunia.

Sistem ini adalah sistem pembelajaran berasaskan laman web yang menyerupai pendidikan dunia sebenar dengan menyatukan konsep pendidikan konvensional. Misalnya, guru-guru boleh memberi 
tugasan, ujian dan markah secara maya, sementara para pelajar boleh menghantar kerja rumah mereka dan menyemak markah yang diperoleh melalui aplikasi VLE Frog. Ibu bapa pula boleh berkomunikasi dengan guru-guru dan pihak pentadbir sekolah boleh menyusun kalendar sekolah dan memaparkan notis melalui Internet. Aplikasi VLE Frog boleh diakses di mana-mana, pada bila-bila masa dengan adanya sambungan Internet [7].

Tujuh konsep asas pelaksanaan aplikasi VLE Frog di sekolah iaitu pertama id pengguna dan kata laluan yang disediakan adalah percuma, kedua menyediakan url untuk pengguna mengakses kepada VLE melalui dalam atau luar 1Bestarinet, ketiga bahan pengajaran yang mudah di akses pada bila-bila masa, keempat aplikasi ini menjimatkan masa guru untuk berkongsi bahan pengajaran, kelima murid, guru dan ibu bapa boleh berinteraksi melalui widget forum, keenam warga sekolah boleh mengakses maklumat sekolah di mana-mana sahaja dan ketujuh memudahkan ibu bapa untuk melihat dan meninjau perkembangan pendidikan anak-anak sekolah [7].

\section{Metodologi Kajian}

Kajian ini merupakan kajian gabungan atau mix method iaitu kajian kuantitatif dan kajian kualitatif. Bagi kajian kuantitatif penyelidik telah menggunakan kaedah instrumen soal selidik dan pemerhatian manakala untuk kajian kualitatif pula penyelidik telah menganalisis dokumen melalui jurnal-jurnal ilmiah dan artikel- artikel kajian lepas. Instrumen soal selidik yang dibina melalui konsep adaptasi kajian lepas telah disahkan melalui dua kaedah iaitu kesahan kandungan melalui sekumpulan pakar rujuk (face validity) dan kesahan konstruk melalui analisis faktor pengesahan (Confirmatory Factor Analysis - CFA). Kutipan data menggunakan borang soal selidik telah yang dijalankan ke atas 367 orang guru Pendidikan Islam sekolah rendah di Negeri Selangor. Data-data daripada borang soal selidik telah dianalisis dengan menggunakan statistik deskriptif iaitu nilai min, sisihan piawai dan statistik inferensi melalui ujian korelasi Pearson.

\section{Analisa Dapatan dan Perbincangan}

\subsection{Fungsi dan Peranan Aplikasi VLE Frog di Peringkat Sekolah Rendah di Malaysia}

Hasil analisis terhadap jurnal-jurnal ilmiah dan artikel-artikel kajian lepas mendapati sistem VLE Frog telah memberi impak dan manfaat yang besar kepada warga pendidik khususnya terhadap murid dan guru. Medium VLE Frog adalah "one stop shop" di mana ia adalah sebuah kedai yang mengeluarkan produk pendidikan untuk menyelesaikan teknologi pendidikan dan menyokong pengajaran di sekolah [8]. Jadual 1 memaparkan hasil analisis artikel-artikel kajian lepas sekitar tahun 2013 hinggan 2018.

Jadual 1. Analisis Artikel Pilihan Sekitar Tahun 2013-2018

\begin{tabular}{|c|c|c|}
\hline \multirow{2}{*}{ Penulis / Artikel } & \multicolumn{2}{|c|}{ Fungsi dan Peranan Terhadap } \\
\hline & Murid & Guru \\
\hline $\begin{array}{l}\text { Aplikasi Persekitaran Pengajaran Maya (Frog VLE) Dalam Kalangan Guru Sains } \\
\text { [9] }\end{array}$ & & $\sqrt{ }$ \\
\hline $\begin{array}{l}\text { Keberkesanan Kemahiran Komunikasi Di kalangan Guru dalam Penggunaan } \\
\text { Persekitaran Pembelajaran Maya (Frog VLE) [5]. }\end{array}$ & & $\sqrt{ }$ \\
\hline How a VLE Can Have A Measurable Impact Upon Your School [8]. & $\sqrt{ }$ & $\sqrt{ }$ \\
\hline $\begin{array}{l}\text { Teachers' Beliefs and TPACK Toward Frog VLE Integration in Special Education } \\
\text { (Hearing Impairment) Classroom [10]. }\end{array}$ & $\sqrt{ }$ & $\sqrt{ }$ \\
\hline $\begin{array}{l}\text { Persepsi Guru Terhadap Ciri-Ciri Inovasi VLE Frog Di Sekolah Di WP Kuala } \\
\text { Lumpur, WP Putrajaya Dan Negeri Selangor [11]. }\end{array}$ & $\sqrt{ }$ & $\sqrt{ }$ \\
\hline $\begin{array}{l}\text { Amalan Pengajaran Guru Kurikulum Bersepadu Dini Menggunakan Aplikasi VLE } \\
\text { Frog Di Sekolah Agama Bantuan Kerajaan Negeri Selangor [12]. }\end{array}$ & & $\sqrt{ }$ \\
\hline
\end{tabular}

Penggunaan sistem VLE Frog telah menjadi semakin biasa dalam kalangan pelajar di Malaysia. Satu platform pembelajaran yang paling canggih dan menaik taraf sistem pendidikan berdasarkan Pelan Pembangunan Pendidikan Malaysia 2013- 2025. Justeru itu, analisis dapatan kajian mendapati fungsi dan peranan sistem VLE Frog telah memberikan kesan yang besar kepada guru dengan meningkatkan kualiti pengajaran guru, merapatkan jurang hubungan antara guru dengan murid secara maya, memudahkan urusan pengajaran dan pembelajaran di dalam kelas dan meningkatkan penggunaan inovasi dalam kalangan guru. Manakala pembelajaran dalam kalangan murid akan 
meluaskan pengetahuan dan membantu murid memperoleh maklumat dan mengaplikasikan maklumat dengan mudah.

\subsection{Cabaran Keberkesanan Penggunaan VLE Frog Di Peringkat Sekolah Rendah Di Malaysia}

Hasil dapatan yang diperoleh melalui instrumen soal selidik pula mendapati empat faktor penggunaan aplikasi VLE Frog di peringkat sekolah rendah iaitu kesediaan guru, kemahiran VLE Frog, sokongan pentadbir sekolah dan sikap guru. Tiga faktor berada pada tahap tinggi iaitu kesediaan guru berada pada nilai min 3.83 dan sisihan piawai 0.292 , sokongan pentadbir sekolah berada pada nilai min 3.82 dan sisihan piawai 0.298 diikuti sikap guru berada pada nilai 3.80 dan sisihan piawai 0.37 manakala faktor kemahiran VLE Frog berada pada tahap sederhana dengan nilai min 3.28 dan sisihan piawai 0.541. Kajian ini disokong dengan kajian yang dijalankan oleh Maimun Aqsha Lubis, Wan Nurul Syuhada' Wan Hassan, \& Mohd Isa Hamzah [9] mendapati tahap kesediaan Guru Pendidikan Islam terhadap penggunaan multimedia dalam pengajaran Pendidikan Islam berada pada tahap sederhana tinggi.

Manakala menurut Ummu Salma Mohiddin \& Fariza Khalid [13] mendapati guru tidak berminat menggunakan VLE Frog kerana kurang kemahiran terhadap aplikasi tersebut. Namun, menurut Kaur \& Hussein [14] dan Siaw Nyuk Hiong \& Agatha Francis Umbit [10] sikap guru merupakan faktor yang mempengaruhi kesediaan guru menggunakan VLE Frog dalam pengajaran sama ada guru tersebut mempunyai tahap pengetahuan yang tinggi ataupun tidak.

Jadual 2. Rumusan Analisis Deskriptif Faktor Keberkesanan Aplikasi VLE Frog

\begin{tabular}{|l|c|c|c|}
\hline \multicolumn{1}{|c|}{ Faktor Keberkesanan } & Jumlah (N) & Min & Sisihan Piawai \\
\hline Kesediaan Guru & 367 & 3.83 & 0.292 \\
\hline Kemahiran VLE Frog & 367 & 3.28 & 0.541 \\
\hline Sokongan Pentadbir Sekolah & 367 & 3.82 & 0.298 \\
\hline Sikap Guru & 367 & 3.80 & 0.370 \\
\hline
\end{tabular}

Hal ini menunjukkan gabungan faktor keberkesanan seperti kesediaan guru, kemahiran VLE Frog guru, sokongan pentadbir sekolah dan sikap guru akan mendorong guru untuk lebih bersedia dan melakukan perubahan terhadap sesi pengajaran di dalam kelas.

Jadual 3. Rumusan Analisis Korelasi Faktor Keberkesanan Penggunaan Aplikasi VLE Frog

\begin{tabular}{|ll|r|r|r|r|}
\hline & & $\begin{array}{c}\text { Kesediaan } \\
\text { Guru }\end{array}$ & $\begin{array}{c}\text { Kemahiran } \\
\text { VLE Frog }\end{array}$ & $\begin{array}{c}\text { Sokongan } \\
\text { Pentadbir Sekolah }\end{array}$ & $\begin{array}{r}\text { Sikap } \\
\text { Guru }\end{array}$ \\
\hline \multirow{3}{*}{ Kesediaan Guru } & Pearson Correlation & 1 & $.466^{* *}$ & $.374^{* *}$ & $.526^{* *}$ \\
& Sig. (2-tailed) & & .000 & .000 & .000 \\
& $N$ & 367 & 367 & 367 & 367 \\
\hline \multirow{2}{*}{ Kemahiran VLE } & Pearson Correlation & $.466^{* *}$ & 1 & $.309^{* *}$ & $.395^{* *}$ \\
Frog & Sig. (2-tailed) & .000 & & .000 & .000 \\
& $N$ & 367 & 367 & 367 & 367 \\
\hline \multirow{2}{*}{ Sokongan Pentadbir } & Pearson Correlation & $.374^{* *}$ & $.309^{* * *}$ & 1 & $.364^{* *}$ \\
Sekolah & Sig. (2-tailed) & .000 & .000 & .000 \\
& $N$ & 367 & 367 & 367 & 367 \\
\hline \multirow{3}{*}{ Sikap Guru } & Pearson Correlation & $.526^{* *}$ & $.395^{* *}$ & $.364^{* *}$ & 1 \\
& Sig. (2-tailed) & .000 & .000 & .000 & \\
& $N$ & 367 & 367 & 367 & 367 \\
\hline
\end{tabular}


Dapatan analisis korelasi pula mendapati setiap faktor mempunyai hubungan signifikan yang positif walaupun berada pada tahap lemah dan sederhana. Nilai hubungan signifikan berada antara nilai $r=0.309$ hingga $r=0.526$. Maka jelas walaupun hubungan setiap faktor adalah lemah dan sederhana namun keperluan setiap faktor sangat diperlukan dalam usaha membina kesediaan penggunaan dalam kalangan guru di peringkat sekolah rendah. Kajian Norhannan Ramli [15] mendapati daya kekuatan dalaman guru sangat signifikan dengan hubungan guru tersebut dengan prestasi. Selain itu kajian turut mengesahkan bahawa faktor motivasi, komitmen dan kepuasan kerja guru Pendidikan Islam berfungsi sebagai mediator bagi prestasi guru Pendidikan Islam tersebut. Hal ini membuktikan sistem ini dibina dan dibangunkan supaya mampu memperluas jaringan hubungan antara murid dengan guru, guru dengan pentadbir sekolah dan pentadbir sekolah dengan komuniti sekeliling.

\subsection{Cadangan Penyelesaian Terhadap Masalah Yang Dihadapi Bagi Penggunaan VLE Frog di Peringkat Sekolah Rendah di Malaysia}

Melalui penyelidikan ini, kesediaan guru didapati mempengaruhi penggunaan aplikasi VLE Frog dalam kalangan guru. Faktor luaran seperti kemahiran VLE Frog, sokongan pentadbir sekolah dan sikap guru merupakan penyokong sampingan terhadap kesediaan dan penerimaan guru untuk menggunakan aplikasi VLE Frog. Justeru itu, para guru Pendidikan Islam khususnya perlu mempunyai sikap positif dan bersedia untuk melakukan perubahan terhadap pengajaran mata pelajaran Pendidikan Islam di sekolah. Hal ini bagi meningkatkan lagi minat dan keseronokan murid mempelajari dan memahami pembelajaran Pendidikan Islam tanpa perlu rasa takut dan membosankan.

Di samping itu, para pentadbir sekolah boleh menjalankan pemantauan secara berterusan dan berkala kepada pada guru supaya proses mentransformasikan sistem pendidikan negara sentiasa berada pada landasan yang betul dan teratur. Penetapan visi dan misi yang jelas akan melahirkan satu anjakan paradigma yang baik dan tersusun sesuai dengan hasrat kerajaan Malaysia bagi melestarikan penggunaan teknologi maklumat secara maksimum dalam pelbagai bidang khususnya pendidikan. Sehubungan dengan itu, KPM perlulah memandang serius perkara ini supaya penggunaan aplikasi VLE Frog dalam kalangan guru dapat dipertingkatkan ke arah meningkatkan kualiti pendidikan masa kini khususnya bagi mata pelajaran Pendidikan Islam di peringkat sekolah rendah. Gesaan pihak kementerian kepada guru supaya mengamalkan PAK-21 perlulah seiring dengan bentuk latihan dan kemahiran yang harus dibekalkan kepada guru-guru di sekolah.

\section{Rumusan}

Aplikasi VLE Frog merupakan satu sistem pembelajaran maya yang akan memberi impak terhadap pengetahuan dan kemahiran warga pendidik khususnya murid-murid di peringkat sekolah rendah. Penggunaan teknologi maklumat sesuai dengan kehendak pasaran dunia masa kini yang berkehendakkan teknologi maklumat digunakan semaksimum yang boleh khususnya dalam dunia pendidikan. Hubungan antara elemen kemahiran VLE Frog, sokongan pentadbir sekolah dan sikap guru menjelaskan bahawa elemen ini saling bertindak balas dalam menghasilkan penerimaan kepada sesuatu perkara. Apabila membincangkan tentang penerimaan VLE Frog maka sikap positif guru akan memberi impak yang baik kepada penerimaan dan penggunaan guru terhadap aplikasi VLE Frog di dalam kelas. Ciri- ciri asas seorang guru yang berkualiti adalah meliputi kualiti pengajaran dan pembelajaran, kualiti personaliti, penguasaan ilmu pengetahuan dan kemahiran, pengintegrasian teknologi maklumat dan persekitaran guru Pendidikan Islam [12]. Hal ini merupakan satu tugas besar yang perlu direalisasikan oleh seorang guru khususnya guru Pendidikan Islam pada zaman ledakan teknologi maklumat masa kini.

\section{Rujukan}

[1] Kementerian Pendidikan Malaysia. (2012). Frog VLE. Retrieved January 5, 2017, from http://frogasia.com/ms/1bestarinet-2/

[2] Embi, M. A. (2016). Pemikiran dan Reka Bentuk Semula: Pengajaran dan Pembelajaran Abad $\mathrm{Ke}$-21. Bangi, Selangor: Penerbit Universiti Kebangsaan Malaysia. Retrieved from http://www.ukm.edu.my/penerbit 
[3] Kementerian Pelajaran Malaysia. (2013). Laporan Awal Ringkasan Eksekutif: Pelan Pembangunan Pendidikan Malaysia 2013-2025. Kuala Lumpur: Kementerian Pelajaran Malaysia.

[4] Kementerian Kewangan Malaysia. (2013). Maklum Balas Ke Atas Laporan Ketua Audit Negara : Siri 3. Putrajaya.

[5] Azlah, M. J. N., \& Fariza, K. (2014). Keberkesanan Kemahiran Komunikasi Di kalangan Guru dalam Penggunaan Persekitaran Pembelajaran Maya (Frog VLE). Pengajaran Sumber Dan Teknologi Maklumat: Impaknya Ke Atas Penyelidikan Dalam Pendidikan, 63-69.

[6] Kementerian Pendidikan Malaysia. (2015). Surat Siaran Kementerian Pendidikan Malaysia Bilangan 1 Tahun 2015: Pelaksanaan Penggunaan Pelantar Persekitaran Pembelajaran Maya 1BestariNet Kementerian Pendidikan Malaysia (KPM). Retrieved from http://btpnkl.weebly.com/uploads/1/4/5/8/14580296/surat_siaran_kpm_bil_1_ta hun_2015.pdf

[7] Kementerian Pendidikan Malaysia. (2010). Rancangan Malaysia Ke-10: Bab 5: Membangun dan Mengekalkan Modal Insan. Rancangan Malaysia Kesepuluh (RMKe-10), 192-251. Retrieved from http://www.moe.gov.my/my/rmk10

[8] Haron, D. (2015). How a VLE Can Have A Measurable Impact Upon Your School. International Education In The Digital Age, 27-30.

[9] Lubis, M. A., Hassan, W. N. S., \& Hamzah, M. I. (2017). Tahap Pengetahuan dan Kesediaan Guru-Guru Pendidikan Islam Sekolah Menengah Di Selangor Terhadap Penggunaan Multimedia Dalam Pengajaran Pendidikan Islam. Asean Comparative Education Research Journal on Islam and Civilization, 1(1), 1-13.

[10] Hiong, S. N., \& Umbit, A. F. (2015). A Pilot Study on Factors Affecting The Use of Frog Virtual Learning Environment. Jurnal Pendidikan IPG, 12, 1-17. Retrieved from http://www.ipbl.edu.my/portal/penyelidikan/jurnalpapers/jurnal2015/Siaw NH_Agatha.pdf

[11] Shahaimi, S., \& Khalid, F. (2017). Persepsi Guru Terhadap Ciri-Ciri Inovasi Vlefrog Di Sekolah Di WP Kuala Lumpur, WP Putrajaya Dan Negeri Selangor. In Simposium Pendidikan diPeribadikan: Perspektif Risalah An-Nur (pp. 226-236).

[12] Jasmi, K. A., (2011). Pendidikan Islam: Cabaran di Alaf Baru. In Seminar Pendidikan Islam (pp. 1-15). Retrieved from http://eprints.utm.my/41072/2/KamarulAzmiJasmi2011_Pendidikan IslamCabara nAlafBaru.pdf

[13] Mohiddin, U. S., \& Khalid, F. (2014). Tahap Pengetahuan Guru Sekolah Rendah dalam Penggunaan VLE Frog untuk Pengajaran \& Pembelajaran. In The 4th International Conference on Learner Diversity (Vol. 50, pp. 780-788). Retrieved from http://eric.ed.gov/ ?id=EJ826493

[14] Kaur, T., \& Hussein, N. (2015). Teachers' Readiness to Utilize Frog VLE: A Case Study of a Malaysian Secondary School. British Journal of Education, Society \& Behavioural Science, 5(1), 20-29. https://doi.org/10.9734/BJESBS/2015/11965

[15] Ramli, N. (2016). Prestasi Guru Pendidikan Islam Berasaskan Daya Kekuatan Dalaman, Kepimpinan Pengetua dan Iklim Sekolah. Universiti Malaya. 